\title{
Muscle-Bone Crosstalk in Chronic Kidney Disease: The Potential Modulatory Effects of Exercise
}

\author{
Diogo V. Leal ${ }^{1}\left([) \cdot\right.$ Aníbal Ferreira $^{2,3}$ (1) $\cdot$ Emma L. Watson $^{4}\left([) \cdot\right.$ Kenneth R. Wilund $^{5} \cdot$ João L. Viana $^{1}$ (1)
}

Received: 29 September 2020 / Accepted: 25 November 2020 / Published online: 2 January 2021

(c) The Author(s), under exclusive licence to Springer Science+Business Media, LLC part of Springer Nature 2021

\begin{abstract}
Chronic kidney disease (CKD) is a prevalent worldwide public burden that increasingly compromises overall health as the disease progresses. Two of the most negatively affected tissues are bone and skeletal muscle, with CKD negatively impacting their structure, function and activity, impairing the quality of life of these patients and contributing to morbidity and mortality. Whereas skeletal health in this population has conventionally been associated with bone and mineral disorders, sarcopenia has been observed to impact skeletal muscle health in CKD. Indeed, bone and muscle tissues are linked anatomically and physiologically, and together regulate functional and metabolic mechanisms. With the initial crosstalk between the skeleton and muscle proposed to explain bone formation through muscle contraction, it is now understood that this communication occurs through the interaction of myokines and osteokines, with the skeletal muscle secretome playing a pivotal role in the regulation of bone activity. Regular exercise has been reported to be beneficial to overall health. Also, the positive regulatory effect that exercise has been proposed to have on bone and muscle anatomical, functional, and metabolic activity has led to the proposal of regular physical exercise as a therapeutic strategy for muscle and bone-related disorders. The detection of bone- and muscle-derived cytokine secretion following physical exercise has strengthened the idea of a cross communication between these organs. Hence, this review presents an overview of the impact of CKD in bone and skeletal muscle, and narrates how these tissues intrinsically communicate with each other, with focus on the potential effect of exercise in the modulation of this intercommunication.
\end{abstract}

Keywords Muscle $\cdot$ Bone $\cdot$ Ckd $\cdot$ Exercise $\cdot$ Myokines $\cdot$ Osteokines

\section{Introduction}

Chronic kidney disease (CKD) has recently been defined as a 'model of accelerated aging', influencing the human body in a patently comparable fashion to aging, with an elevated

João L. Viana

jviana@ismai.pt

1 Research Center in Sports Sciences, Health Sciences and Human Development, CIDESD, University Institute of Maia, ISMAI, Maia, Portugal

2 Department of Nephrology, Curry Cabral Hospital, Hospital Centre of Central Lisbon, Lisbon, Portugal

3 Nova Medical School, Lisbon, Portugal

4 Department of Cardiovascular Sciences, University of Leicester, Leicester, UK

5 Department of Kinesiology and Community Health, University of Illinois At Urbana-Champaign, Champaign, IL, USA liability for locomotor disorders, specifically fractures, falls, and limited mobility, loss of function, and frailty [1, 2]. CKD patients often develop mineral and bone disorders (MBD), which include disturbances in the homeostasis of calcium $\left(\mathrm{Ca}^{2+}\right)$, phosphorus $\left(\mathrm{P}^{+}\right)$, vitamin $\mathrm{D}$, and parathyroid hormone (PTH); abnormalities in bone turnover, mineralization, and volume; or vascular or other soft tissue calcifications [3]. With these impairments potentially contributing to increased fracture occurrence [4], and with CKD patients having a higher prevalence of cardiovascular disease [5], the combination of these significantly increases the rate of morbidity, hospitalizations and mortality $[1,2]$.

Despite earlier research on skeletal health focusing upon bone and mineral abnormalities, recently it has been recognized that sarcopenia also has a major role in reduced musculoskeletal health in CKD [6, 7]. CKD patients suffer severe skeletal muscle wasting [8], with CKD being pathologically associated with a gradual and severe deterioration in overall skeletal muscle mass, function and strength [6, 
9-11]. This is particularly evident in advanced stages of the disease [10], with this compromised skeletal muscle health increasing the risk of mortality in CKD.

Skeletal muscle is attached to bone both anatomically and physiologically, as they cooperate to allow movement and locomotion. Muscle and bone act in parallel to support and regulate the muscles' functions in order to produce strength and exert forces to allow for functional independence [7, 12]. This led to the development of the term 'bone-muscle unit' in the late 90's, strengthened by the linear association between total body mineral content and lean mass reported in a large study of individuals $(n=1450)$ ranging from 2 to 87 years of age [13]. However, it is currently known that the bone-muscle crosstalk is not solely a mechanism for bone formation through the application of mechanical load to skeletal muscle, but an ongoing communication between myokines and osteokines that act together to activate muscle metabolism $[12,14,15]$. Whilst movement and locomotion are enabled through the skeletal muscle's contractile properties (sliding filaments in the sarcomeres) [16], wholebody metabolism is facilitated by the continuous crosstalk between these tissues at a molecular, endocrine and substrate level [12, 17-19]. Indeed, the homeostatic regulation of muscle and bone is influenced by both endogenous and exogenous factors, that intrinsically collaborate to allow for the regulation of structure and function $[15,19,20]$.

The growing knowledge about the interactions between bone and muscle, and the influence of exercise on both these tissues has important implications for clinical practice, especially when targeting a reduction of the burden of co-morbidities in CKD patients. This review focuses on the cross communication between muscle and bone, seeking to highlight the potential modulatory effect of exercise on these tissues, highlighting its usefulness as a novel therapeutic strategy to improve muscle and bone parameters, and consequently overall health and quality of life in patients with CKD.

\section{Skeletal Muscle and Bone Metabolism in CKD}

\section{Bone Metabolism in CKD}

Epidemiologically, as treatments have improved CKD patients now are able to live longer lives with survival rates much improved. However, the incidence of skeletal fractures has been higher in recent years. Older CKD patients have especially high fracture rates, in part because the incidence of skeletal fractures increases with aging [4], and also because fracture risk is exacerbated as CKD progresses [21]. The loss of bone tissue observed in CKD is caused in part by a disturbed replacement of bone tissue, referred to as bone remodelling. Physiological bone remodelling is a process that coordinates the relation between bone formation and resorption by constantly eliminating old bone and replacing it with resynthesized protein-rich, mineralization of the matrix [22]. Indeed, the rate of bone remodelling (influenced by exogenous and endogenous factors) regulates the quality of bone extracellular matrix, which in turn may alter bone strength. In CKD patients, the systemic mineral metabolism and the overall composition of bone tissue is altered in parallel with the progression of the disease [23], with studies showing a direct correlation between declines in glomerular filtration rate (GFR) and deteriorating bone microarchitecture (which may estimate bone quality) and remodelling [24]. This scenario has been described as a broader systemic disorder associated with CKD that includes extra-skeletal calcifications, termed CKD-MBD [3]. Despite most CKD patients showing histologic signs of elevated bone turnover alongside high concentration levels of PTH [25, 26], low bone turnover has been reported as the predominant MBD in both pre-dialysis and haemodialysis patients [27, 28]. Alongside this deterioration in bone turnover, mineralization and strength, CKD-MBD is characterised by an abnormal metabolism of $\mathrm{Ca}^{2+}, \mathrm{P}^{+}$, and vitamin $\mathrm{D}$, soft-tissue calcifications, as well as an overactivity of PTH [24], with the latter mediating a significant loss in cortical bone in this population [29].

Moreover, the process of bone remodelling, is regulated through the action of certain osteogenic proteins, such as the receptor activator of nuclear factor- $\kappa \mathrm{B}$ ligand (RANKL) [22]. The presence of the myogenic Interleukin (IL)-6 drives the occurrence of osteoclastogenesis by activating the secretion of osteoblast- and osteocyte-induced receptor activator of nuclear factor $\mathrm{\kappa}-\mathrm{B}$ (RANK). This triggers an elevated expression of RANKL [30], following loss of brain and muscle aryl hydrocarbon receptor nuclear translocator-like protein 1 (BMAL1) [31], a transcription factor that when absent in osteoblasts, increases the ability to support osteoclastogenesis [31]. However, while the activation of RANKL induces osteoclastogenesis, an elevation in osteoprotegerin (OPG) inhibits this process. The binding of RANKL to its receptor RANK, triggers a cascade of signalling events that induce differentiation, activity and survival of osteoclasts [32]. However, OPG may bind to RANKL as well, which prevents the latter binding to RANK [33]. This action of OPG may be important in restraining osteoclastogenesis, and therefore preventing bone loss [33]. However, reports on RANKL and OPG levels in CKD, especially in haemodialysis patients, have shown conflicting outcomes. While OPG concentrations are consistently reported as pathologically high in haemodialysis patients [34-36], reports on RANKL levels are inconsistent, with higher [37], lower [34], or similar [38] levels, when compared with healthy individuals. In pre-dialysis patients, serum OPG was observed to be 
progressively elevated with reductions in creatinine clearance [39].

An important bone-derived endocrine pathway that influences certain tissues systemically is osteocalcin (OCN), which signals through sclerostin (Sost). OCN is secreted by osteoblasts and then activated by osteoclasts during the process of bone resorption. High levels of OCN are commonly found in CKD patients [40], potentially due to decreased renal clearance, increased bone metabolism or even a combination of these two factors, with the progressive increase in circulating OCN correlating with intact PTH and Bone Alkaline Phosphatase (BALP) levels [41]. Moreover, the increase in OCN levels may reflect the severity of the bone lesion [42]. Yet, serum levels of OCN's uncarboxylated form (ucOCN) were observed to be considerably lower in predialysis patients compared with healthy individuals, with close associations with subclinical atherosclerosis in CKD found [43]. Despite the utility of OCN and BALP as indicators of bone formation, these molecules alone cannot provide sufficient evidence to determine the underlying histologic variants of skeletal diseases [40]. Furthermore, osteocyteand osteoblast-derived fibroblast growth factor (FGF)-23 has been proposed as one of the main bone-derived endocrine markers involved in the regulation of systemic phosphate and vitamin D [44]. In the presence of the co-receptor klotho, FGF-23 binds to the FGF receptor, with its expression being activated by osteocyte-derived PHEX and Dmp1 [45]. In CKD, FGF-23 has been observed to be associated with muscle atrophy through inhibition of insulin/IGF signalling in skeletal muscle [46]. However, its influence in bone metabolism is still being investigated, as in vitro studies observed no alteration in $\mathrm{C} 2 \mathrm{C} 12$ myotube function, and ex vivo FGF-23 treatment did not alter Soleus muscle contractility [47].

\section{Muscle Metabolism in CKD}

Several terms associated with muscle wasting in chronic diseases such as protein-energy wasting (PEW), cachexia and sarcopenia have been used interchangeably [48]. In CKD, the catabolic state induced by this condition has been proposed to be associated with elevated uraemia and PEW [49]. This is a consequence of underlying complications such as acidosis, systemic inflammation, insulin resistance, and increased levels of myostatin, eventually leading to a reduction in muscle protein synthesis [50-52] and an increase in protein degradation. Indeed, PEW has been suggested as an adequate predictor of mortality in some cohorts of CKD patients [53, 54], with PEW being also proposed as the initial state of a continuous process leading to cachexia, as both have comparable catabolic pathways and physiopathology [48], with the noticeable clinical feature of cachexia being further associated with inflammation and weight reduction in adults [55]. Therefore, cachexia has been described as an underlying cause of sarcopenia [55], the latter defining the loss of muscle mass and function [56] and relating with dynapenia (loss of muscle strength [57]), which in CKD patients increase with disease progression [58]. Given that muscle metabolism influences many metabolic pathways [18, 59-62], the maintenance of skeletal muscle mass, strength and force production in this population is highly clinically significant. Indeed, a longitudinal study completed on 103 patients undergoing peritoneal dialysis who were followed for an 8-year period found that higher lean body mass (assessed by creatinine kinetics) predicts longer overall patient survival, while low lean body mass is associated with increased mortality and morbidity rates [63].

The regulation of skeletal muscle mass is modulated by continuous changes in the rate at which muscle protein synthesis and breakdown occur, with turnover rates in healthy adults averaging $\sim 1 \%$ to $2 \%$ muscle protein per day [64], equating to approximately $300-600 \mathrm{~g}$ of remodelled protein every day. Yet, the balance between muscle mass synthesis/ breakdown, which is known to be disturbed in many catabolic diseases, such as CKD, is regulated by a network of signalling pathways which transmit external stimuli to intracellular pathways leading to gene transcription activation/ deactivation $[65,66]$. This ongoing protein turnover occurring in muscle tissue facilitates the continuous replacement of aged or damaged proteins, therefore contributing to the maintenance of healthy skeletal muscle [67]. Thus, skeletal muscle wasting in CKD may be explained by a dysregulated protein synthesis and degradation. Contrarily to commonly held notions, it has been reported that in the basal state both synthesis and catabolism are elevated in maintenance haemodialysis patients [68], which therefore leads to dialysis patients having a rapid turnover of unhealthy muscle, with protein dysfunction in dialysis patients recently proposed to be mediated by integrin [69]. In pre-dialysis patients, mRNA expression markers of protein degradation were observed to be elevated, with the myogenic Pax7 and MyoD expression being lower, when compared with age-matched healthy controls [70].

There are several possible mechanisms that may be involved in the initiation of skeletal muscle wasting in these patients. This sarcopenia-related protein degradation may be explained by several systems, such as the ubiquitin-proteasome system, where multiple ubiquitin molecules attach to specific proteins marking them for rapid degradation following enzymatic activation, with these polyubiquitinated proteins being subsequently degraded by the proteasome [71]. Another mechanism of sarcopenia-related protein degradation is lysosomal proteolysis, which despite the low presence of lysosomes in adult skeletal muscle, these organelles have been observed to be stimulated in a variety of pathological conditions, specifically through the action 
of the protease cathepsin known to regulate extracellular matrix homeostasis, autophagy, apoptosis, glomerular permeability, and inflammation in CKD [72]. More recently, the role of autophagosomes in muscle pathology, doublemembrane vesicles formed from intracellular lysosomal degradation, has also been described [73]. In mice, CKD has been observed to induce autophagy and mitochondrial dysfunction in skeletal muscle [74]. Excessive activation of this proteolytic- and lysosomal-dependent degradation leads to skeletal muscle loss of mass and strength [75]. Moreover, given the large inter-individual variability relating to length of disease, differences in co-morbidities and medications, predominating factors are likely to vary between individuals. Broadly these factors include inflammation, metabolic acidosis, myostatin and oxidative stress acting upon protein balance, but also function of skeletal muscle satellite cells (MuSc) [50, 76]. Systemically, this relationship between protein synthesis and degradation is manipulated by myokines such as myostatin and IL-6, respectively. Myostatin, a member of the transforming growth factor- $\beta$ (TGF- $\beta$ ) superfamily of cytokines, is known as a suppressor of skeletal muscle tissue growth, with elevated concentrations showing to be correlated with muscle disuse, injury and sarcopenia [77]. Myostatin secretion to the circulation signals as an endocrine cytokine [78], with both plasma and intramuscular levels of myostatin known to be elevated in early stage CKD [79, 80]. Myostatin affects muscle wasting by disrupting MuSc function and an up regulation of E3 ligases instigating protein breakdown by the proteasome [50]. Interesting, in murine CKD models an anti-myostatin peptibody normalised protein metabolism, alleviating atrophy and systemic inflammation [81], highlighting this as a potentially important candidate to be considered for therapies to alleviate skeletal muscle wasting. Interestingly, activated signal transducer and activator of transcription 3 (p-Stat3) was found in CKD-induced mice, leading to the hypothesis that CKD-derived muscle wasting is initiated by this mechanism [81]. Following this, Zhang et al. observed in $\mathrm{C} 2 \mathrm{C} 12$ myotubes that p-Stat 3 muscle wasting may stimulate myostatin [82]. Their team also observed a robustly elevated muscle p-Stat 3 and an increased expression of IL-6 and tumor necrosis factor-alpha (TNF- $\alpha$ ) in CKD compared with healthy subjects, associating a p-Stat 3 activation with muscle damage in human CKD patients as well [82].

Chronic systemic inflammation is common in CKD and IL-6 signalling has been associated with myogenesis and subsequent skeletal muscle growth through the regulation of the proliferative capability of muscle stem cells [83]. IL-6 knockout mice were shown to have an impaired hypertrophic response to overloading [84], with this hypertrophic mechanism requiring both an elevation in net protein synthesis and accretion of new nuclei from MuSc. Interestingly, the impaired hypertrophy detected in IL-6 null rodents has been attributed to a reduced accretion of myonuclei, while protein synthesis pathways remain unchanged [84]. This blunted myonuclei sensitivity may therefore be observed as a consequence of the faulty proliferation and migration of MuSc in the absence of IL-6 [84]. In CKD, IL-6 is commonly observed to be chronically elevated [85], which is largely caused by an increased oxidative stress and a potentially reduced clearance due to impaired renal function. In addition, skeletal muscle expression of TNF- $\alpha$ and IL- 6 have been reported to be higher in CKD patients $[80,86]$ strongly suggesting that an inflammatory environment also exists within skeletal muscle which has important implications for increasing protein degradation.

\section{Skeletal Muscle-Bone Crosstalk}

\section{Myokines and Bone Metabolism}

Beyond its negative effect on skeletal muscle growth, myostatin has been reported to be involved in poor bone metabolism, by negatively impacting bone remodelling, eliciting osteoclastogenesis, and reducing bone formation [77]. Inhibition of myostatin in the osteogenic differentiation of bone marrow stem cells elicited an elevation in the expression of osteogenic growth factors, such as insulinlike growth factor 1 (IGF-1) [87]. In myostatin-inhibited mice, elevated osteogenesis was observed, with a general increase in bone density, strength and mineralization [77]. However, despite the well-defined influence of myostatin in bone remodelling, the mechanism by which it occurs is still unclear. It has been proposed that myostatin supresses miRNA-128 in osteocyte-derived exosomes, as well as stimulating the production of Sost, RANKL and Dickkopf Wnt signalling pathway inhibitor 1 (DKK1) [88]. This has been proposed due to the influence that miRNA-128 has on inhibiting Wnt signalling, and the rapid extent to which osteocyte-derived exosomes are taken up by osteoblasts, leading to reduced osteoblastogenesis and impaired bone formation [89].

Whereas myostatin has been clearly defined as a catabolic myokine on bone tissue remodelling, the musclederived IGF-1, FGF-2, and IL-15 exert clear anabolic effects in bone metabolism. Both IGF-1 and FGF-2 elicit similar anabolic mechanisms in osteoblasts, increasing osteoblast proliferation and accelerating bone formation [14]. While IGF-1 regulates bone anabolism as a response to an elevation in osteoblast survival and proliferation [90], FGF-2 has been proposed to be secreted following disruption of plasma membrane in response from either injury or mechanical muscle contraction, rather than exocytosis [14]. Recently, FGF-2 has also been observed to attenuate glucocorticoid-mediated bone resorption through inhibition of Sost signalling [91], 
reinforcing its anabolic effects on bone metabolism. Additionally, higher circulating levels of muscle-derived IL-15 have been associated with increased bone mineral content in mice models [92]. In human CKD patients, increased circulating levels of IL-15 have been observed, despite lower levels of IL-15 in Staphylococcus enterotoxin A-stimulated and in influenza A vaccine-stimulated supernatants [93]. Low levels of IGF-1 have been associated with increased muscle wasting [94], and lower bone mineral density in CKD patients [95]. Additionally, previous research observed an association between low levels of IGF-1 and mortality, with lower IGF-1 concentrations detected in haemodialysis patients who died, compared with survivors [96]. However, FGF-2 concentrations are poorly described in CKD and remain uncertain, despite FGF-2 mRNA expression being significantly upregulated in interstitial and tubular cells in end-stage kidney disease [97].

Another myokine involved in bone metabolism is irisin. Irisin is an endocrine myokine secreted from skeletal muscle in response to an increased expression of peroxisome proliferator-activated receptor $\gamma$ co-activator-1 $\alpha(\mathrm{PGC} 1 \alpha)$. Irisin's primary target organ has been proposed to be bone tissue, based on compelling evidence on its influence in improving cortical bone mass and geometry, without affecting the transdifferentiation of adipose tissue in in male mice. This highlights irisin's role as the molecular transducer responsible for the cross-talk in the muscle-bone unit during physical activity [98]. Interestingly, irisin and its precursor FNDC5 expression in skeletal muscle were reported to be elevated in myostatin knockout rodents [99]. Plasma levels of irisin have been reported to be lower in CKD patients, with previous research observing approximately $59 \%$ lower resting concentration levels in stage 5 CKD patients, when compared with age- and sex-matched healthy individuals [100]. Moreover, irisin levels were reduced as renal function declined in a sample of 532 patients across stages 1-5 CKD, even after adjustment for adjusted for age, gender and body mass index [101].

\section{Osteokines and Muscle Metabolism}

A converging body of evidence suggests there is crosstalk within a bone-muscle unit [102], with both these organs being impacted by CKD. The influence of elements such as reduced bone density (commonly referred to as bone quantity), and low bone microarchitecture, when taken together, may lead to a significant reduction in mechanical strength. The relationship of these factors with fall risk and reduced neuromuscular strength may consequently lead to accelerated skeletal fractures [4]. In addition to providing structure, protecting organs, and enabling movement, bone tissue is the main reservoir of minerals such as $\mathrm{Ca}^{2+}$ and $\mathrm{K}^{+}$, which are fundamental for muscle contraction.
The homeostatic regulation of bone and skeletal muscle is dependent on endogenous and exogenous factors which act intrinsically to regulate structure and function. Dietary protein, vitamin $\mathrm{D}$ and $\mathrm{Ca}^{2+}$ modulate bone metabolism, with protein and perhaps also vitamin $\mathrm{D}$ downregulating catabolic mechanisms. These also activate anabolic signalling pathways such as OCN, IGF-1, and phosphorylated mammalian target-of-rapamycin (mTOR) [103], which in turn are associated with increased bone density [104], lean mass, strength and function $[103,105]$. The signalling of OCN in myofibers has been shown to be necessary for muscle mass maintenance, following observation of increased protein synthesis both in old and 10-month-old female mice muscle cells [106]. In this study [106], a reduction in myofibers cross-sectional area was observed, but muscle strength was unchanged in OCN-deleted mice compared to control littermates, suggesting OCN favours muscle mass maintenance, yet does not affect strength. Additionally, 12-month-old mice lacking the receptor GPRC6A in all cells were observed to have considerably low skeletal muscle mass and body weight, when compared to control littermates [107]. Despite Gprc6a gene being expressed in myofibers and OCN signalling through this receptor to regulate muscle function during exercise [108], a similar reduction in muscle weight was observed in 12-month-old compound mutant mice lacking one allele of Osteocalcin and one allele of Gprc6a, specifically in myofibers. This provides direct genetic evidence that OCN may be an important modulator of muscle mass [106, 108]. Furthermore, the influence of OCN in regulating muscle mass through regulation of protein synthesis in myofibers has been strengthened, following detection of $\mathrm{OCN}$-induced phosphorylation of S6K1, an mTOR target protein [106]. Interestingly, S6K1 was interrupted by Torin1, through its inhibitory action on the mTOR complex [106], highlighting the effects of $\mathrm{OCN}$ in promoting myotube-derived protein synthesis.

Recently it has been observed that the anti-anabolic Sost acts to induce osteoblastogenesis [109]. This mechanism occurs following inhibition of Wnt signalling upon binding with the receptors LRP5 and LRP6, therefore inhibiting osteogenesis [109]. Following identification of these two receptors in myocytes [109], it has been reported that in vitro and ex vivo evidence suggest that cultured osteocytes may potentially elicit myogenesis and contractile force, proposing that Wnts could be mediators of bone to muscle signalling, likely via modulation of intracellular $\mathrm{Ca}^{2+}$ signalling and the Wnt/ $\beta$-Catenin pathway [110], which is antagonistic to its known action in bone tissue. However, a recent crosssectional study in elderly Koreans with sarcopenia had contrasting results, with serum Sost concentrations inversely correlated with muscle mass [111], denoting an identical catabolic effect as occurs in bone. Studies of the role of Wnt signalling in CKD have been increasing in recent years, with 
immunohistochemical evidence of kidney biopsy samples emphasising the presence of several common Wnt proteins in CKD [112]. These are commonly associated with renal tubule specific inhibition of Wnt secretion, resulting in the inhibition of fibroblast gene expression activation and exacerbation of kidney fibrosis [112], with its influence in CKD muscle poorly described.

Another bone marker that exerts its influence on skeletal muscle metabolism is RANK. RANK may be expressed in skeletal muscle, and activation of the NF- $\mathrm{BB}$ pathway induces an inhibition of myogenic differentiation, leading to skeletal muscle dysfunction and loss [113]. In mouse models, mRNA expression of RANK-RANKL was indeed observed to occur highly in both muscle and bone, with the overexpression of RANKL being reported as the cause for decreased muscle mass and force [114]. An increased expression of RANKL and reduced expression of OPG following osteoblast-exposure to PTH in hyperparathyroidism has been observed [115]. These authors [115] cultured mouse primary bone marrow stromal osteoblasts with bovine PTH peptide [bPTH (1-34)] for up to 28 days, and observed that PTH significantly up-regulates RANKL mRNA, and inhibits OPG expression at all stages of osteoblast differentiation. This suggests exposure to PTH is associated with elevated osteoclastogenesis. However, despite the antagonistic reports on RANKL concentrations reported in CKD [34, 37, 38], the effect of PTH on the up-regulation of RANKL mRNA leading to elevated bone resorption has been confirmed to occur in haemodialysis patients [37]. Figure 1 depicts the skeletal muscle-bone crosstalk through the influence of the myokines and osteokines described in this review.

\section{The Potential Effects of Exercise in the Modulation of the Skeletal Muscle-Bone Communication in CKD}

\section{Effects of Exercise on Osteokines in CKD}

Highlighting the noteworthy progress in understanding bone and skeletal muscle disease in CKD in recent years, physical exercise has been advised as a preventative and therapeutic method against bone disorders such as osteoporosis [116]. The majority of studies report exercise has significant effects on bone mass $[117,118]$ and mineral density [119], through the inhibition of bone resorption [117] and promotion of bone formation [120]. Additionally, regular exercise has been reported to improve the metabolic activity

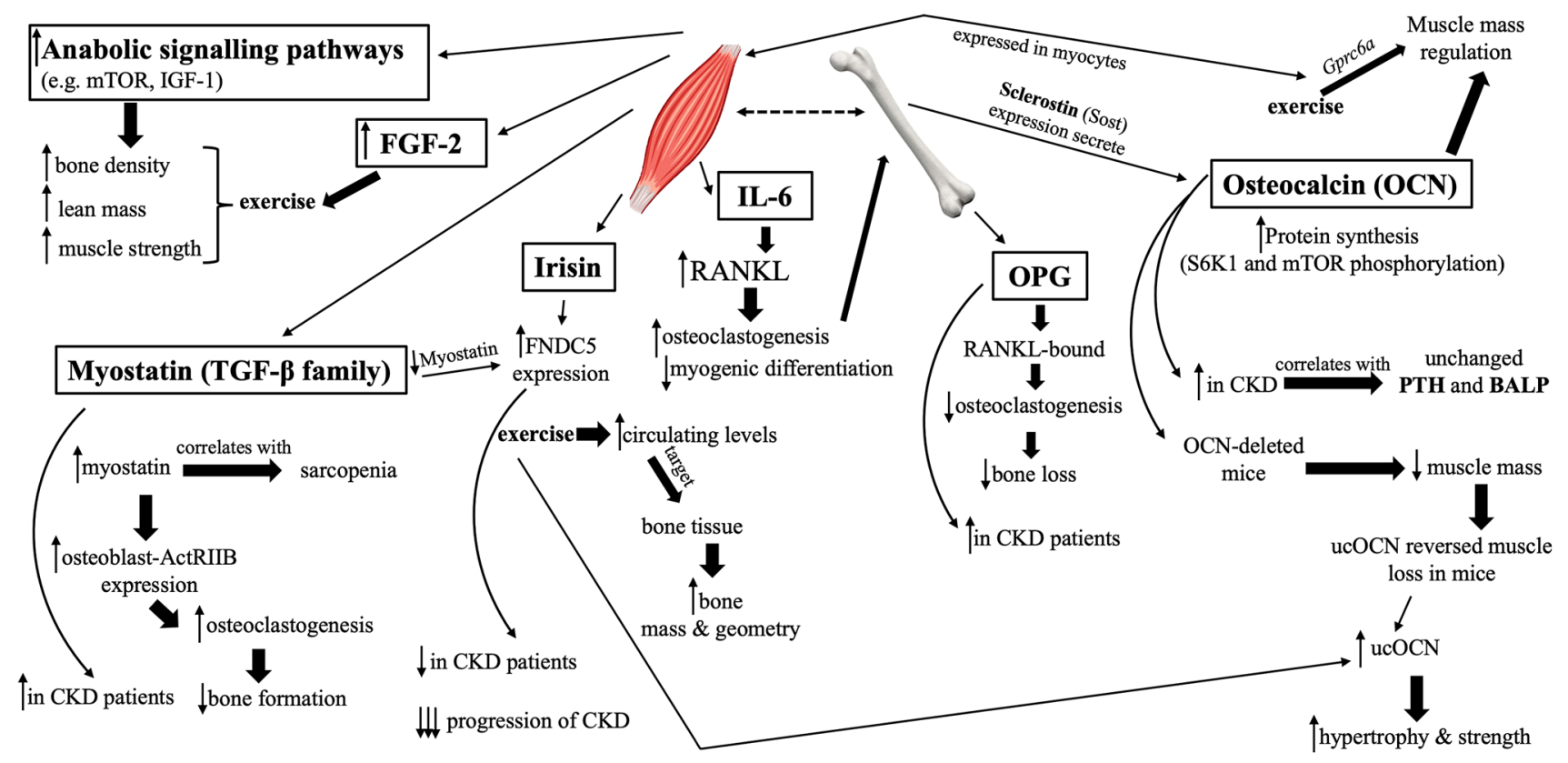

Fig. 1 Relationship between anabolic signalling pathways, myokines and osteokines in bone and skeletal muscle metabolism in Chronic Kidney Disease. CKD is associated with dysregulated myokine and osteokine activity, and increased circulating cytokines. Myostatin correlates with sarcopenia and is elevated in CKD. It induces an increased expression of ActRIIB from osteoblasts and is therefore associated with increased osteoclastogenesis and consequently reduced bone formation. Muscle-derived IL-6 elicits increased RANKL expression, which in turn increases osteoclastogenesis and reduces myogenic differentiation. However, the bone derived OPG (abnormally high in CKD) may bind to RANKL to reverse this catabolic effect. Increased $\mathrm{OCN}$ is observed in CKD, directly correlating with increased protein synthesis (S6K1 and mTOR phosphorylation), with exercise playing a pivotal role in upregulating Gprc6a eliciting an adequate muscle mass regulation. Exercise also has a positive regulatory effect on increasing bone density, lean mass and muscle strength, by eliciting elevated FGF-2 responses and anabolic signalling pathways such as mTOR and IGF-1, as well as increased ucOCN 
for contraction [121] and regulation of skeletal muscle mass and function [122-125], making it a promising novel therapeutic strategy for muscle-related disorders.

The demonstration that the bone-derived hormone osteocalcin favours muscle functions during exercise raises the question of whether this hormone may also regulate muscle mass. On a functional level, reduced muscle mass was observed in OCN-deleted mice [108], with this condition being reversed following administration of OCN's uncarboxylated form (ucOCN) in older mice [106]. Moreover, ucOCN was also shown to elevate in response to exercise of different types and durations [126-128], which in turn has been observed to be associated with certain cellular and metabolic effects such as the promotion of the survival and function of pancreatic $\beta$-cells, increase in insulin secretion and sensitivity, and in glucose uptake. These data support the perspective that ucOCN is involved in muscle hypertrophy and strength, as observed in adult mice, following its signalling through its receptor GPRC6A [107]. Indeed, elevations of both ucOCN and muscle-derived IL-6 levels have been observed in mice following endurance exercise (treadmill-run for 4 days, $17 \mathrm{~min} /$ day with increasing speed from 10 to $30 \mathrm{~cm} / \mathrm{s}$ ), with these changes being dependent of one another [129]. The expected exercise-induced elevated response of OCN has not been observed in IL-6-deficient rodents, with this effect being corrected following injection of IL-6 [129].

In a recent systematic review we have observed a positive relation of resistance exercise interventions on bone health in CKD patients, suggesting however that a greater focus on conducting prospective studies and long-term randomized controlled trials to examine the influence of different exercise modalities on bone parameters is necessary [130]. A study completed on 39 stage 3-4 CKD patients reported no chronic influence of exercise in markers of bone metabolism (including ucOCN) following 24 weeks of low to moderate intensity aerobic training (30 min, 3x/week, with $10 \mathrm{~min}$ increments at weeks 4 and 8) [131]. However, a threemonth aerobic exercise program (three sessions weekly), where haemodialysis patients completed a total $30 \mathrm{~min}$ of self-paced, intradialytic cycling elicited an elevation in bone mineral density and skeletal muscle functional capacity (i.e. greater six-minute walk distance covered), when compared to before the exercise program [132]. Also, six months of intradialytic resistance exercise using elastic bands (72 sessions in total) did not influence OCN concentrations. However, there was an elevation in OPG $(\sim 15 \%)$, which was hypothesized to contribute to bone loss prevention in haemodialysis patients [133].

In line with and corroborating the therapeutic effects of exercise in bone metabolism, an eight-week period of intradialytic resistance exercise has induced robust elevations in resting concentrations of BALP and serum 1,25-dihydroxyvitamin D in haemodialysis patients [134]. Regular exercise has been shown to potentially prevent bone loss through improvements in bone mineral density as a result of an increased expression of bone markers such as BALP [135] and OPG [136]. Moreover, resistance exercise has shown more promising osteogenic effects compared with aerobic exercise [130], though research comparing modes of exercise are limited, and more research is needed.

There is increasing research highlighting exercise as an appropriate therapeutic strategy to reduce the chronic impact of diseases [137]. A study completed on healthy male individuals has observed increased concentrations of OPG following eight days of acute, weight-bearing endurance exercise [138]. Elevated levels of OPG, despite unchanged RANKL, have also been observed after one year of aerobic (fast walking) exercise in postmenopausal women [139], whereas a significant reduction in RANKL was reported to occur following eight weeks of resistance training in male rats [140]. Furthermore, mechanical strain imposed by a flexcell bioflex instrument on murine bone stromal cells induced a significant reduction in RANKL [141], highlighting the potential positive effects of resistance exercise in the maintenance of bone and muscle quality and strength. However, increased RANKL was observed $5 \mathrm{~min}, 1 \mathrm{~h}$ and $24 \mathrm{~h}$ after high-intensity, low impact exercise in young adult males [142], but no change was observed in RANKL or OPG following eight months of either resistance or aerobic exercise in older women [143]. These contrasting results highlight the need for more research examining the effects of exercise on these bone-muscle markers, with the existing data showing promising results as to the applicability of exercise interventions as an important therapeutic strategy in fighting bone and muscle loss of quality and function.

\section{Effects of Exercise on Myokines in CKD}

CKD patients undergoing haemodialysis are known to be considerably less physically active than age-matched healthy individuals [144]. Moreover, a study performed on CKD patients separated into two groups depending on the severity of the disease (stage 3-4 CKD and haemodialysis patients) highlights similarly low physical activity levels among predialysis patients (i.e. stages 3-4) and patients undergoing HD [145]. Despite the multifactorial causes for muscle wasting and reduced muscle quality in CKD, physical inactivity has been extensively proposed to be a major contributor [146-148]. A 2-year observational study completed on 134 patients (60 on haemodialysis, 28 on peritoneal dialysis, 46 CKD 4-5) reported a $35 \%$ reduction in skeletal muscle mass determined by thigh cross-sectional area on computed tomography in the first year of treatment, with muscle loss being more pronounced in pre-dialysis patients [149]. 
Myokines such as irisin, IL-15, and IL-6 have been consistently shown to be released by skeletal muscle in response to exercise [150-152], with these biomarkers exerting beneficial physiological and metabolic effects in both skeletal muscle and bone, and even in immune cells, directly driving a systemic anti-inflammatory effect in the body $[82,153]$. The skeletal muscle secretome connects with bone through the influence of several molecules, such as IGF-1, FGF-2 and myostatin. Interestingly, it has been reported that splice variants of muscle IGF-1 mRNA expression are increased to the same extent after five months of endurance, resistance, or combined exercise programs in haemodialysis patients, despite unchanged lean mass when comparing before to after the training period [154]. The authors [154] suggested that the design of the exercise program may not have been appropriate to elicit a skeletal muscle adaptive response due to the patients' low physical capacity and function. However, an exercise-induced overexpression of IGF-1 was observed in healthy muscle from aging individuals, which was speculated to be a compensatory mechanism to overcome the aging-associated anti-anabolic effect of muscle protein synthesis [155]. This exacerbated IGF-1 signalling in haemodialysis patients may not necessarily be indicative of an anabolic mechanism, but instead may be an aberrant response in overstimulated skeletal muscle tissue. Therefore, caution should be taken when interpreting results from exercise interventions (with focus on modality, duration and intensity) and thoroughly define how these may influence IGF-1 signalling to appropriately account for the influence of inter and intradialytic regulation of skeletal muscle activity.

There is some evidence that skeletal muscle's osteoinducible cellular populations may directly influence bone formation and its capability to regenerate [156]. Interestingly, a study completed in rodents observed that highintensity muscle contractions during hindlimb unloading (defined as resistance exercise) performed during disuse promoted cortical bone geometry and formation rate restoration, and suppressed unloading-induced elevations in Sost-positive osteocytes [157], with Sost promoting osteoblast apoptosis through inhibition of certain signalling pathways, leading to reductions in bone formation [158]. Corroborating these authors [157], an elevation in myocyte-released FGF-2, a signalling protein with osteogenic properties involved in tissue repair and cell growth, was shown to have a significant positive influence on bone formation in mice with oestrogen deficiency [159], with this myokine known to be released in response to mechanically-induced plasma membrane disruption and mechanical stretching [160]. The mechanically-induced release of FGF-2 in response to eccentric muscle contraction and plasma membrane disruption may therefore be a pathway by which physical activity/exercise and bone formation are connected [14, 159].

We have shown compelling evidence of the anti-inflammatory effects of exercise in CKD [161]. Macrophages are a type of leucocytes present in skeletal muscle tissue that are central in muscle repair and pathogen clearance, mechanism regulated through a myofibers-immune cells crosstalk [153]. It has been proposed that macrophages may induce a calcifying phenotype, mainly via BALP expression in human vascular smooth muscle cells in the presence of interferon- $\gamma$ [162]. However, evidence of the effects of exercise in the crosstalk between immune cells (such as macrophages), bone and skeletal muscle in CKD patients is limited, with the few existing studies examining this interaction being conducted in rodents due to the invasiveness of sampling procedures. In CKD patient muscle biopsy samples, we have observed a reduced inflammatory IL- 6 and TNF- $\alpha$ response was observed to an acute bout of exercise following a period of resistance exercise training, but neither unaccustomed nor accustomed exercise resulted in a change in myogenin or MyoD mRNA expression, observing that exercise creates a large inflammatory response within the muscle, no longer present following regular training [163]. Nonetheless, genomic associations have been reported to be predictive of peak bone density and lean body mass [164], and singlenucleotide polymorphisms in the genes that regulate myostatin and the vitamin $\mathrm{D}$ receptor showing direct associations with the reduction of muscle and bone mass [19], with CKD altering the circulating concentrations and cellular responses of these markers. Importantly, a study applied two different exercise protocols (a resistance, muscle overload protocol, and a treadmill-run) to examine muscle protein metabolism and progenitor cell function in CKD-induced mice (by subtotal nephrectomy) [165]. Both reduced the CKD-associated muscle proteolysis and improved phosphorylation of Akt and the transcription factor FoxO1 [165]. Interestingly, the authors observed that two weeks of resistance exercise elicited an increase in levels of mTOR (a mediator of protein synthesis), normalising protein synthesis in the muscles of CKD-induced mice [165]. Moreover, this exercise intervention increased muscle progenitor cellular activity and numbers, determined by the amounts of MyoD and myogenin mRNAs [165]. As pharmacological myostatin inhibition reversed muscle mass loss, suppressed inflammatory cytokines, increased protein synthesis and enhanced satellite cell function in mice [81], these information may boost the possible application of exercise as a therapeutic strategy, with myostatin mRNA shown to gradually decrease in the $24 \mathrm{~h}$ after moderate exercise in healthy subjects [166]. Recently, it was proposed the bone-derived osteocalcin signalling in myofibers is required for exercise adaptation, which is linked with improved muscle function, promoting muscle IL-6 secretion during exercise [108]. 
Of note, it is known that the influence of IL- 6 in bone tissue occurs through osteoblast signalling resulting in elevated RANKL expression and osteoclastogenesis [129]. Additionally, these authors [129] have observed that IL-6-deficient mice have repeatedly shown compromised exercise-induced muscle activity, whereas those lacking IL-6 receptor in myofibers did not show compromised muscle function. However, those lacking the IL-6 receptor in osteoblast instead have mirrored the effect of total IL-6 deficiency, indicating the regulatory effect of OCN in muscle function. This suggests that the benefits of IL- 6 in muscle function are regulated through the skeleton, with exercise (muscle contraction) playing a pivotal role in the modulation of this mechanism.

With exercise being known for its beneficial effects on new bone formation and bone mineral density [167], irisin (known to be released into the circulation in response to physical activity and exercise [168]) has been suggested as a major molecular modulator on increasing the protective effect that skeletal muscle may yield on bone tissue [98]. In fact, conditioned medium from primary myoblasts (obtained from exercised muscle and cultured ex vivo) were observed to boost the amount of BALP positive colonies in a culture of undifferentiated bone marrow stromal cells, with the conditioned medium-differentiated osteoblasts from exercised muscle expressing higher levels of BALP and collagen type I mRNA, yet a reverted effect was observed when conditioned medium were spiked with a neutralizing antibody against irisin [169]. A period of six months of intradialytic resistance exercise did not elicit any changes in resting levels of irisin in haemodialysis patients, despite an increase in muscle mass as a result of the program was observed [170]. Indeed, a 12-month period of exercise completed in 151 pre-dialysis CKD patients robustly increased leg and whole-body lean mass, with an elevation in myostatin levels observed [171]. The authors [171] randomly divided the participants into two groups to complete either $90 \mathrm{~min}$ of strength or balance training. Both groups also completed an additional $60 \mathrm{~min}$ of endurance exercise (150 min/week in total). These data may suggest that, despite lower levels of irisin observed in CKD patients compared with healthy controls [170], an exercise-induced increase in muscle mass may have potentially occurred due to the increased myostatin responsiveness [171]. As a reminder, myostatin is a negative regulator of muscle mass. This is in contrast with what has been observed elsewhere [171], where plasma myostatin was significantly correlated with muscle mass and physical performance at baseline, yet these relationships were blunted after 12 months of training, in pre-dialysis patients with healthy-like C-reactive protein and albumin levels. Myostatin expression is known to be intrinsically related with IL-6 activity and upregulated in an inflammatory status [82, 172], suggesting this as a major cause for protein wasting in CKD. Interestingly, in non-inflamed individuals, myostatin levels have been observed to be within normal range, when compared with healthy individuals [173]. Therefore, an exercise-induced elevation in myostatin levels in CKD patients as observed elsewhere [171], may be interpreted as an expected physiological response to increased muscle mass, since myostatin is primarily expressed in skeletal muscle [77]. Contrastingly, a study completed on 60 patients on maintenance haemodialysis have reported that higher myostatin levels were associated with lower muscle function, measured via handgrip strength on the dominant upper limb [174]. It may be suggested that these contrasting results may be clarified by the different stages of the disease, with haemodialysis patients suffering from more severe inflammatory states than pre-dialysis patients. Still, this highlights the need for further research, and for caution when using exercise interventions to examine myostatin responsiveness in this population. Additionally, despite irisin being proposed to be an exercise-dependent myokine, to the authors' knowledge, there are very limited studies examining this relationship in CKD.

\section{Final Remarks}

While countless dialysis patients may appear too frail to engage in moderate to vigorous exercise sessions, those who can undertake such programs experience considerable benefits [175]. Less vigorous exercise (aerobic, resistance or other alternative forms), may also be valuable, challenging the concern clinicians have about the application of resistance exercise to fight skeletal muscle loss of mass and function, and disproving the gradually less common conviction of exercise as a contraindication to the patients' health [175]. Indeed, a recently published prospective cohort study on 89 patients with CKD stages $3 \mathrm{~b}-5$ with a follow-up period of 3.3 years reported that each $1 \mathrm{~cm}^{2}$ increase in muscle size (quadriceps) and $10 \mathrm{~m}$ improvement on the incremental shuttle walk test was associated with a $38 \%$ and $3 \%$ reduction in risk of mortality, respectively [176].

Naturally, CKD patients who undergo dialysis treatment, either peritoneal dialysis or haemodialysis, experience an imposed reduction of physical activity due to inevitable sedentary time during treatment. Recognised as key risk factors for unfavourable outcomes in both predialysis patients and those undergoing renal replacement treatment, there is still debate about the best therapeutic strategies to reduce sarcopenia and frailty. The intrinsic communication between muscle and bone tissues has been comprehensively narrated in this review. It arises that by therapeutically acting on one of these organs (e.g. to treat a metabolic dysfunction), one can get beneficial results on the other, with the net result possibly being potentiated 
when acting holistically [177]. This may be the case of exercise interventions, recently described as a "polypill" to aid in the treatment of morbidity and to improve overall health status, given its encouraging pleiotropic outcomes on all organs and systems [137].

The outcomes from this review on the potential influence of exercise on the attenuation of the detrimental impact of CKD in bone and skeletal muscle tissues and its metabolism and cross communication, highlights the urgent need for the massive implementation of worldwide exercise programs, as it has been thoroughly promoted by multi-national organizations such as the Global Renal Exercise (GREX) network. The influence of formalized groups demonstrates increased global interest in this area, which may in turn positively influence the prevention of the physical dysfunction associated with CKD, but especially with patients undergoing dialysis treatment. This is the case of the ongoing intradialytic exercise programs implemented in Mexico, Portugal, Canada and Germany which highlight the importance of demonstrating that, in addition to improving overall patient health, exercise programs need to be cost-effective, possibly through reduction of medications, improving dialysis compliance or even reducing hard outcomes such as hospitalizations and mortality [178].

The authors consider the most important take-home message from this review is the importance of implementing exercise as a therapeutic strategy to reduce muscle and bone impairments, aiming to ameliorate physical function and improve the overall quality of life across the spectrum of CKD. Effective counselling and advice on the implementation of physical activity and exercise, and the rising influence of the interdisciplinary communication between kidney health providers and specialised exercise physiologists is essential to guide an effective and crucial implementation of exercise programs worldwide.

Acknowledgements Research Center in Sports Sciences, Health Sciences and Human Development, CIDESD, is supported by the Portuguese Foundation of Science and Technology (UID/04045/2020).

Author Contributions JLV had the idea for the article. DVL drafted versions of the manuscript with input and revisions from JVL, AF, ELW and KRW. All authors contributed to the article and approved the submitted version.

Funding Research Center in Sports Sciences, Health Sciences and Human Development, CIDESD, is supported by the Portuguese Foundation of Science and Technology (UID/04045/2020).

Data Availability Not applicable.

Code Availability Not applicable.

\section{Compliance with Ethical Standards}

Conflict of interest The authors declare that the present narrative review article was conducted in the absence of any commercial or financial conflict of interest.

\section{References}

1. Stenvinkel P, Larsson TE (2013) Chronic kidney disease: a clinical model of premature aging. Am J Kidney Dis 62:339-351

2. Kooman JP, Kotanko P, Schols AMWJ, Shiels PG, Stenvinkel P (2014) Chronic kidney disease and premature ageing. Nat Rev Nephrol 10:732-742

3. Moe S, Drüeke T, Cunningham J, Goodman W, Martin K, Olgaard K, Ott S, Sprague S, Lameire N, Eknoyan G (2006) Definition, evaluation, and classification of renal osteodystrophy: a position statement from kidney disease: improving global outcomes (KDIGO). Kidney Int 69:1945-1953

4. Pimentel A, Ureña-Torres P, Zillikens MC, Bover J, Cohen-Solal M (2017) Fractures in patients with CKD — diagnosis, treatment, and prevention: a review by members of the European calcified tissue society and the European renal association of nephrology dialysis and transplantation. Kidney Int 92:1343-1355

5. Gansevoort RT, Correa-Rotter R, Hemmelgarn BR, Jafar TH, Heerspink HJL, Mann JF, Matsushita K, Wen CP (2013) Chronic kidney disease and cardiovascular risk: epidemiology, mechanisms, and prevention. Lancet 382:339-352

6. Moorthi RN, Avin KG (2017) Clinical relevance of sarcopenia in chronic kidney disease. Curr Opin Nephrol Hypertens 26:219-228

7. Avin KG, Moorthi RN (2015) Bone is not alone: the effects of skeletal muscle dysfunction in chronic kidney disease. Curr Osteoporos Rep 13:173-179

8. Zelle DM, Klaassen G, Van Adrichem E, Bakker SJL, Corpeleijn E, Navis G (2017) Physical inactivity: a risk factor and target for intervention in renal care. Nat Rev Nephrol 13:152-168

9. Ortiz A, Sanchez-Niño MD (2019) Sarcopenia in CKD: a roadmap from basic pathogenetic mechanisms to clinical trials. Clin Kidney J 12:110-112

10. De Souza VA, Oliveira D, Barbosa SR, Corrêa JODA, Colugnati FAB, Mansur HN, Fernandes NMDS, Bastos MG (2017) Sarcopenia in patients with chronic kidney disease not yet on dialysis: analysis of the prevalence and associated factors. PLoS ONE 12:e0176230

11. Hirakawa Y, Jao TM, Inagi R (2017) Pathophysiology and therapeutics of premature ageing in chronic kidney disease, with a focus on glycative stress. Clin Exp Pharmacol Physiol 44:70-77

12. Tagliaferri C, Wittrant Y, Davicco MJ, Walrand S, Coxam V (2015) Muscle and bone, two interconnected tissues. Ageing Res Rev 21:55-70

13. Ferretti JL, Capozza RF, Cointry GR, García SL, Plotkin H, Filgueira MLA, Zanchetta JR (1998) Gender-related differences in the relationship between densitometric values of whole-body bone mineral content and lean body mass in humans between 2 and 87 years of age. Bone 22:683-690

14. Hamrick MW (2012) The skeletal muscle secretome: an emerging player in muscle-bone crosstalk. Bonekey Rep 1:60

15. Kirk B, Feehan J, Lombardi G, Duque G (2020) Muscle, bone, and fat crosstalk: the biological role of myokines, osteokines, and adipokines. Curr Osteoporos Rep 184:388-400

16. Huxley HE (1969) The mechanism of muscular contraction. Science 164:1356-1365 
17. Colaianni G, Mongelli T, Colucci S, Cinti S, Grano M (2016) Crosstalk between muscle and bone via the muscle-myokine irisin. Curr Osteoporos Rep 14:132-137

18. Wolfe RR (2006) The underappreciated role of muscle in health and disease. Am J Clin Nutr 84:475-482

19. Trajanoska K, Rivadeneira F, Kiel DP, Karasik D (2019) Genetics of bone and muscle interactions in humans. Curr Osteoporos Rep 17:86-95

20. Riley LA, Esser KA (2017) The role of the molecular clock in skeletal muscle and what it is teaching us about muscle-bone crosstalk. Curr Osteoporos Rep 15:222-230

21. Naylor KL, Garg AX, Zou G et al (2015) Comparison of fracture risk prediction among individuals with reduced and normal kidney function. Clin J Am Soc Nephrol 10:646-653

22. Honma M, Ikebuchi Y, Kariya Y, Suzuki H (2014) Regulatory mechanisms of RANKL presentation to osteoclast precursors. Curr Osteoporos Rep 12:115-120

23. Drüeke TB, Massy ZA (2016) Changing bone patterns with progression of chronic kidney disease. Kidney Int 89:289-302

24. Hou Y-C, Lu C-L, Lu K-C (2018) Mineral bone disorders in chronic kidney disease. Nephrology 23:88-94

25. Levin A, Bakris GL, Molitch M, Smulders M, Tian J, Williams LA, Andress DL (2007) Prevalence of abnormal serum vitamin D, PTH, calcium, and phosphorus in patients with chronic kidney disease: results of the study to evaluate early kidney disease. Kidney Int 71:31-38

26. Moranne O, Froissart M, Rossert J et al (2009) Timing of onset of CKD-related metabolic complications. J Am Soc Nephrol 20:164-171

27. Sprague SM, Bellorin-Font E, Jorgetti V et al (2016) Diagnostic accuracy of bone turnover markers and bone histology in patients with CKD treated by dialysis. Am J Kidney Dis 67:559-566

28. Malluche HH, Mawad HW, Monier-Faugere MC (2011) Renal osteodystrophy in the first decade of the new millennium: analysis of 630 bone biopsies in black and white patients. J Bone Miner Res 26(13):68-1376

29. Nickolas TL, Stein EM, Dworakowski E et al (2013) Rapid cortical bone loss in patients with chronic kidney disease. J Bone Miner Res 28:1811-1820

30. Udagawa N, Takahashi N, Katagiri T et al (1995) Interleukin (IL)-6 induction of osteoclast differentiation depends on IL-6 receptors expressed on osteoblastic cells but not on osteoclast progenitors. J Exp Med 182:1461-1468

31. Takarada T, Xu C, Ochi H et al (2017) Bone resorption is regulated by circadian clock in osteoblasts. J Bone Miner Res 32:872-881

32. Lacey DL, Boyle WJ, Simonet WS, Kostenuik PJ, Dougall WC, Sullivan JK, Martin JS, Dansey R (2012) Bench to bedside: elucidation of the OPG-RANK-RANKL pathway and the development of denosumab. Nat Rev Drug Discov 11:401-419

33. Ominsky MS, Li X, Asuncion FJ et al (2008) RANKL inhibition with osteoprotegerin increases bone strength by improving cortical and trabecular bone architecture in ovariectomized rats. J Bone Miner Res 23:672-682

34. Doumouchtsis KK, Kostakis AI, Doumouchtsis SK, Tziamalis MP, Tsigris C, Kostaki MA, Perrea DN (2007) sRANKL/ osteoprotegerin complex and biochemical markers in a cohort of male and female hemodialysls patients. J Endocrinol Invest 30:762-766

35. Kazama JJ, Shigematsu T, Yano K, Tsuda E, Miura M, Iwasaki Y, Kawaguchi Y, Gejyo F, Kurokawa K, Fukagawa M (2002) Increased circulating levels of osteoclastogenesis inhibitory factor (osteoprotegerin) in patients with chronic renal failure. Am J Kidney Dis 39:525-532
36. Avbersek-Luznik I, Malesic I, Rus I, Marc J (2002) Increased levels of osteoprotegerin in hemodialysis patients. Clin Chem Lab Med 40:1019-1023

37. Avbersek-Luznik I, Balon BP, Rus I, Marc J (2005) Increased bone resorption in HD patients: is it caused by elevated RANKL synthesis? Nephrol Dial Transplant 20:566-570

38. Albalate M, de la Piedra C, Fernández C, Lefort M, Santana H, Hernando P, Hernández J, Caramelo C (2006) Association between phosphate removal and markers of bone turnover in haemodialysis patients. Nephrol Dial Transplant 21:1626-1632

39. Kazama JJ, Kato H, Sato T, Shigematsu T, Fukagawa M, Iwasaki Y, Gejyo F (2002) Circulating osteoprotegerin is not removed through haemodialysis membrane. Nephrol Dial Transplant 17:1860-1861

40. Razzaque MS (2011) Osteocalcin: a pivotal mediator or an innocent bystander in energy metabolism? Nephrol Dial Transplant 26:42-45

41. Delmas PD, Wilson DM, Mann KG, Riggs BL (1983) Effect of renal function on plasma levels of bone gla-protein. J Clin Endocrinol Metab 57:1028-1030

42. Coen G, Mazzaferro S, Bonucci E, Taggi F, Ballanti P, Bianchi AR, Donato G, Massimetti C, Smacchi A, Cinotti GA (1985) Bone GLA protein in predialysis chronic renal failure. Effects of $1,25(\mathrm{OH}) 2 \mathrm{D} 3$ administration in a long-term follow-up. Kidney Int 28:783-790

43. Zhang M, Ni Z, Zhou W, Qian J (2015) Undercarboxylated osteocalcin as a biomarker of subclinical atherosclerosis in nondialysis patients with chronic kidney disease. J Biomed Sci 22:75

44. Quarles LD (2012) Role of FGF23 in vitamin D and phosphate metabolism: implications in chronic kidney disease. Exp Cell Res 318:1040-1048

45. Lara-Castillo N, Johnson ML (2020) Bone-muscle mutual interactions. Curr Osteoporos Rep 18:408-421

46. Kido S, Hashimoto Y, Segawa H, Tatsumi S, Miyamoto K (2012) Muscle atrophy in patients wirh ckd results from fgf23/klothomediated supression of insulin/igf-i signaling. Kidney Res Clin Pract 31:A44

47. Avin KG, Vallejo JA, Chen NX, Wang K, Touchberry CD, Brotto M, Dallas SL, Moe SM, Wacker MJ (2018) Fibroblast growth factor 23 does not directly influence skeletal muscle cell proliferation and differentiation or ex vivo muscle contractility. Am J Physiol - Endocrinol Metab 315:E594-E604

48. Koppe L, Fouque D, Kalantar-Zadeh K (2019) Kidney cachexia or protein-energy wasting in chronic kidney disease: facts and numbers. J Cachexia Sarcopenia Muscle 10:479-484

49. Jadeja YP, Kher V (2012) Protein energy wasting in chronic kidney disease: an update with focus on nutritional interventions to improve outcomes. Indian J Endocrinol Metab 16:246-251

50. Wang XH, Mitch WE (2014) Mechanisms of muscle wasting in chronic kidney disease. Nat Rev Nephrol 10:504-516

51. Stenvinkel P, Lindholm B, Heimbürger O (2004) Novel approaches in an integrated therapy of inflammatory-associated wasting in end-stage renal disease. Semin Dial 17:505-515

52. Roshanravan B, Gamboa J, Wilund K (2017) Exercise and CKD: skeletal muscle dysfunction and practical application of exercise to prevent and treat physical impairments in CKD. Am J Kidney Dis 69:837-852

53. Beddhu S, Chen X, Wei G, Raj D, Raphael KL, Boucher R, Chonchol MB, Murtaugh MA, Greene T (2017) Associations of protein-energy wasting syndrome criteria with body composition and mortality in the general and moderate chronic kidney disease populations in the United States. Kidney Int Reports 2:390-399

54. Moreau-Gaudry X, Jean G, Genet L, Lataillade D, Legrand E, Kuentz F, Fouque D (2014) A simple protein-energy wasting 
score predicts survival in maintenance hemodialysis patients. $\mathrm{J}$ Ren Nutr 24:395-400

55. Rolland Y, Van Kan GA, Gillette-Guyonnet S, Vellas B (2011) Cachexia versus sarcopenia. Curr Opin Clin Nutr Metab Care $14: 15-21$

56. Santilli V, Bernetti A, Mangone M, Paoloni M (2014) Clinical definition of sarcopenia. Clin Cases Miner Bone Metab 11:177-180

57. Clark BC, Manini TM (2012) What is dynapenia? Nutrition 28:495-503

58. Delmonico MJ, Harris TB, Visser M et al (2009) Longitudinal study of muscle strength, quality, and adipose tissue infiltration. Am J Clin Nutr 90:1579-1585

59. McPherron AC, Guo T, Bond ND, Gavrilova O (2013) Increasing muscle mass to improve metabolism. Adipocyte 2:92-98

60. Argilés JM, Campos N, Lopez-Pedrosa JM, Rueda R, RodriguezMañas L (2016) Skeletal muscle regulates metabolism via interorgan crosstalk: roles in health and disease. J Am Med Dir Assoc 17:789-796

61. Meyer C, Dostou JM, Welle SL, Gerich JE (2002) Role of human liver, kidney, and skeletal muscle in postprandial glucose homeostasis. Am J Physiol - Endocrinol Metab 282:E419-427

62. Zurlo F, Larson K, Bogardus C, Ravussin E (1990) Skeletal muscle metabolism is a major determinant of resting energy expenditure. J Clin Invest 86:1423-1427

63. Huang JW, Lien YC, Wu HY, Yen CJ, Pan CC, Hung TW, Su CT, Chiang CK, Cheng HT, Hung KY (2013) Lean body mass predicts long-term survival in Chinese patients on peritoneal dialysis. PLoS ONE 8:e54976

64. Holwerda AM, Paulussen KJM, Overkamp M, Smeets JSJ, Gijsen AP, Goessens JPB, Verdijk LB, Van Loon LJC (2018) Daily resistance-type exercise stimulates muscle protein synthesis in vivo in young men. J Appl Physiol 124:66-75

65. Glass DJ (2005) Skeletal muscle hypertrophy and atrophy signaling pathways. Int J Biochem Cell Biol 37:1974-1984

66. Sandri M (2008) Signaling in muscle atrophy and hypertrophy. Physiology 23:160-170

67. Burd NA, De Lisio M (2017) Skeletal muscle remodeling: interconnections between stem cells and protein turnover. Exerc Sport Sci Rev 45:187-191

68. van Vliet S, Skinner SK, Beals JW et al (2018) Dysregulated handling of dietary protein and muscle protein synthesis after mixed-meal ingestion in maintenance hemodialysis patients. Kidney Int Reports 3:1403-1415

69. Draicchio F, van Vliet S, Ancu O et al (2020) Integrin-associated ILK and PINCH1 protein content are reduced in skeletal muscle of maintenance hemodialysis patients. J Physiol. https://doi. org/10.1113/JP280441

70. Baker LA, O'Sullivan TF, Robinson KA, Redshaw Z, Graham Brown M, Ashford RU, Smith AC, Watson EL (2020) Establishment and characterisation of primary skeletal muscle cell cultures from patients with advanced chronic kidney disease. BioRxiv. https://doi.org/10.1101/2020.11.16.384263

71. Schwartz AL, Ciechanover A (2009) Targeting proteins for destruction by the ubiquitin system: implications for human pathobiology. Annu Rev Pharmacol Toxicol 49:73-96

72. Cocchiaro P, De Pasquale V, Della MR, Tafuri S, Avallone L, Pizard A, Moles A, Pavone LM (2017) The multifaceted role of the lysosomal protease cathepsins in kidney disease. Front Cell Dev Biol 5:114

73. Lilienbaum A (2013) Relationship between the proteasomal system and autophagy. Int J Biochem Mol Biol 4:1-26

74. Su Z, Klein JD, Du J, Franch HA, Zhang L, Hassounah F, Hudson MB, Wang XH (2017) Chronic kidney disease induces autophagy leading to dysfunction of mitochondria in skeletal muscle. Am J Physiol - Ren Physiol 312:F1128-F1140
75. Sandri M (2011) New findings of lysosomal proteolysis in skeletal muscle. Curr Opin Clin Nutr Metab Care 14:223-229

76. O'Sullivan T, Smith AC, Watson EL (2018) Satellite cell function, intramuscular inflammation and exercise in chronic kidney disease. Clin Kidney J 11:810-821

77. Elkasrawy MN, Hamrick MW (2010) Myostatin (GDF-8) as a key factor linking muscle mass and bone structure. J Musculoskelet Neuronal Interact 10:56-63

78. Huang Z, Chen D, Zhang K, Yu B, Chen X, Meng J (2007) Regulation of myostatin signaling by c-Jun $\mathrm{N}$-terminal kinase in C2C12 cells. Cell Signal 19:2286-2295

79. Bataille S, Chauveau P, Fouque D, Aparicio M, Koppe L (2020) Myostatin and muscle atrophy during chronic kidney disease. Nephrol Dial Transplant. https://doi.org/10.1093/ndt/gfaa129

80. Verzola D, Procopio V, Sofia A et al (2011) Apoptosis and myostatin mRNA are upregulated in the skeletal muscle of patients with chronic kidney disease. Kidney Int 79:773-782

81. Zhang L, Rajan V, Lin E et al (2011) Pharmacological inhibition of myostatin suppresses systemic inflammation and muscle atrophy in mice with chronic kidney disease. FASEB J 25:1653-1663

82. Zhang L, Pan J, Dong Y, Tweardy DJ, Dong Y, Garibotto G, Mitch WE (2013) Stat3 activation links a C/EBP $\delta$ to myostatin pathway to stimulate loss of muscle mass. Cell Metab 18:368-379

83. Muñoz-Cánoves P, Scheele C, Pedersen BK, Serrano AL (2013) Interleukin-6 myokine signaling in skeletal muscle: a doubleedged sword? FEBS J 280:4131-4138

84. Serrano AL, Baeza-Raja B, Perdiguero E, Jardí M, MuñozCánoves P (2008) Interleukin-6 is an essential regulator of satellite cell-mediated skeletal muscle hypertrophy. Cell Metab 7:33-44

85. Stenvinkel P, Ketteler M, Johnson RJ, Lindholm B, Pecoits-Filho R, Riella M, Heimbürger O, Cederholm T, Girndt M (2005) IL-10, IL- 6 , and TNF- $\alpha$ : central factors in the altered cytokine network of uremia - the good, the bad, and the ugly. Kidney Int 67:1216-1233

86. Garibotto G, Sofia A, Procopio V et al (2006) Peripheral tissue release of interleukin-6 in patients with chronic kidney diseases: effects of end-stage renal disease and microinflammatory state. Kidney Int 70:384-390

87. Hamrick MW, Shi X, Zhang W, Pennington C, Thakore H, Haque M, Kang B, Isales CM, Fulzele S, Wenger KH (2007) Loss of myostatin (GDF8) function increases osteogenic differentiation of bone marrow-derived mesenchymal stem cells but the osteogenic effect is ablated with unloading. Bone 40:1544-1553

88. Qin Y, Peng Y, Zhao W et al (2017) Myostatin inhibits osteoblastic differentiation by suppressing osteocyte-derived exosomal microRNA-218: a novel mechanism in muscle-bone communication. J Biol Chem 292:11021-11033

89. Lyu H, Xiao Y, Guo Q, Huang Y, Luo X (2020) The role of bone-derived exosomes in regulating skeletal metabolism and extraosseous diseases. Front Cell Dev Biol 8:89

90. DiGirolamo DJ, Mukherjee A, Fulzele K, Gan Y, Cao X, Frank SJ, Clemens TL (2007) Mode of growth hormone action in osteoblasts. J Biol Chem 282:31666-31674

91. Adhikary S, Choudhary D, Tripathi AK, Karvande A, Ahmad N, Kothari P, Trivedi R (2019) FGF-2 targets sclerostin in bone and myostatin in skeletal muscle to mitigate the deleterious effects of glucocorticoid on musculoskeletal degradation. Life Sci 229:261-276

92. Quinn LS, Anderson BG, Strait-Bodey L, Stroud AM, Argués JM (2009) Oversecretion of interleukin-15 from skeletal muscle reduces adiposity. Am J Physiol - Endocrinol Metab 296:E191-202

93. Mansouri L, Paulsson JM, Moshfegh A, Jacobson SH, Lundahl J (2013) Leukocyte proliferation and immune modulator 
production in patients with chronic kidney disease. PLoS ONE 8:e73141

94. Scicchitano BM, Rizzuto E, Musarò A (2009) Counteracting muscle wasting in aging and neuromuscular diseases: the critical role of IGF-1. Aging (Albany NY) 1:451-457

95. Park SH, Jia T, Qureshi AR, Bárány P, Heimbürger O, Larsson TE, Axelsson J, Stenvinkel P, Lindholm B (2013) Determinants and survival implications of low bone mineral density in endstage renal disease patients. J Nephrol 26:485-494

96. Rashid Qureshi A, Alvestrand A, Divino-Filho JC, Gutierrez A, Heimbürger O, Lindholm B, Bergström J (2001) Inflammation, malnutrition, and cardiac disease as predictors of mortality in hemodialysis patients. J Am Soc Nephrol 13:S28-36

97. Strutz F, Zeisberg M, Hemmerlein B, Sattler B, Hummel K, Becker V, Müller GA (2000) Basic fibroblast growth factor expression is increased in human renal fibrogenesis and may mediate autocrine fibroblast proliferation. Kidney Int 57:1521-1538

98. Colaianni G, Cuscito C, Mongelli T et al (2015) The myokine irisin increases cortical bone mass. Proc Natl Acad Sci U S A 112:12157-12162

99. Shan T, Liang X, Bi P, Kuang S (2013) Myostatin knockout drives browning of white adipose tissue through activating the AMPK-PGC1-Fnde5 pathway in muscle. FASEB J 27:1981-1989

100. Wen MS, Wang CY, Lin SL, Hung KC (2013) Decrease in irisin in patients with chronic kidney disease. PLoS ONE 8:e64025

101. Ebert T, Focke D, Petroff D et al (2014) Serum levels of the myokine irisin in relation to metabolic and renal function. Eur $\mathrm{J}$ Endocrinol 170:501-506

102. Reginster J-Y, Beaudart C, Buckinx F, Bruyère O (2016) Osteoporosis and sarcopenia: two diseases or one? Curr Opin Clin Nutr Metab Care 19:31-36

103. Yang A, Lv Q, Chen F, Wang Y, Liu Y, Shi W, Liu Y, Wang D (2020) The effect of vitamin D on sarcopenia depends on the level of physical activity in older adults. J Cachexia Sarcopenia Muscle 11:678-689

104. Wallace TC, Frankenfeld CL (2017) Dietary protein intake above the current RDA and bone health: a systematic review and metaanalysis. J Am Coll Nutr 36:481-496

105. Verlaan S, Maier AB, Bauer JM et al (2018) Sufficient levels of 25-hydroxyvitamin $\mathrm{D}$ and protein intake required to increase muscle mass in sarcopenic older adults - the PROVIDE study. Clin Nutr 37:551-557

106. Mera P, Laue K, Wei J, Berger JM, Karsenty G (2016) Osteocalcin is necessary and sufficient to maintain muscle mass in older mice. Mol Metab 5:1042-1047

107. Oury F, Sumara G, Sumara O et al (2011) Endocrine regulation of male fertility by the skeleton. Cell 144:796-809

108. Mera P, Laue K, Ferron M et al (2016) Osteocalcin signaling in myofibers is necessary and sufficient for optimum adaptation to exercise. Cell Metab 23:1078-1092

109. Karczewska-Kupczewska M, Stefanowicz M, Matulewicz N, Nikołajuk A, Straczkowski M (2016) Wnt signaling genes in adipose tissue and skeletal muscle of humans with different degrees of insulin sensitivity. J Clin Endocrinol Metab 101:3079-3087

110. Huang J, Romero-Suarez S, Lara N et al (2017) Crosstalk between MLO-Y4 osteocytes and C2C12 muscle cells is mediated by the Wnt/ $\beta$-catenin pathway. JBMR Plus 1:86-100

111. Kim JA, Roh E, Hong S, hyeon et al (2019) Association of serum sclerostin levels with low skeletal muscle mass: the korean sarcopenic obesity study (KSOS). Bone 128:115053

112. Zhou D, Fu H, Zhang L, Zhang K, Min Y, Xiao L, Lin L, Bastacky SI, Liu Y (2017) Tubule-derived wnts are required for fibroblast activation and kidney fibrosis. J Am Soc Nephrol 28:2322-2336
113. Langen RCJ, Schols AMWJ, Kelders MCJM, Wouters EFM, Janssen-Heininger YMW (2001) Inflammatory cytokines inhibit myogenic differentiation through activation of nuclear factor- $\mathrm{\kappa B}$. FASEB J 15:1169-1180

114. Bonnet N, Bourgoin L, Biver E, Douni E, Ferrari S (2019) RANKL inhibition improves muscle strength and insulin sensitivity and restores bone mass. J Clin Invest 129:3214-3223

115. Huang JC, Sakata T, Pfleger LL, Bencsik M, Halloran BP, Bikle DD, Nissenson RA (2004) PTH differentially regulates expression of RANKL and OPG. J Bone Miner Res 19:235-244

116. Russo CR (2009) The effects of exercise on bone. Basic concepts and implications for the prevention of fractures. Clin Cases Miner Bone Metab 6:223-228

117. Alghadir AH, Gabr SA, Al-Eisa ES, Alghadir MH (2016) Correlation between bone mineral density and serum trace elements in response to supervised aerobic training in older adults. Clin Interv Aging 11:265-273

118. Marques EA, Mota J, Carvalho J (2012) Exercise effects on bone mineral density in older adults: a meta-analysis of randomized controlled trials. Age (Omaha) 34:1493-1515

119. Marinho SM, Moraes C, Barbosa DSM, JE, Eduardo JCC, Fouque D, Pelletier S, Mafra D, (2016) Exercise training alters the bone mineral density of hemodialysis patients. J Strength Cond Res 30:2918-2923

120. Adami S, Gatti D, Viapiana O, Fiore CE, Nuti R, Luisetto G, Ponte M, Rossini M (2008) Physical activity and bone turnover markers: a cross-sectional and a longitudinal study. Calcif Tissue Int 83:388-392

121. Joseph AM, Adhihetty PJ, Leeuwenburgh C (2016) Beneficial effects of exercise on age-related mitochondrial dysfunction and oxidative stress in skeletal muscle. J Physiol 594:5105-5123

122. Watson EL, Gould DW, Wilkinson TJ, Xenophontos S, Clarke AL, Vogt BP, Viana JL, Smith AC (2018) Twelve-week combined resistance and aerobic training confers greater benefits than aerobic training alone in nondialysis CKD. Am J Physiol Physiol 314:F1188-F1196

123. Greenwood SA, Koufaki P, Mercer TH et al (2015) Effect of exercise training on estimated GFR, vascular health, and cardiorespiratory fitness in patients with CKD: a pilot randomized controlled trial. Am J Kidney Dis 65:425-434

124. Howden EJ, Coombes JS, Isbel NM (2015) The role of exercise training in the management of chronic kidney disease. Curr Opin Nephrol Hypertens 24:480-487

125. Harada K, Suzuki S, Ishii H et al (2017) Impact of skeletal muscle mass on long-term adverse cardiovascular outcomes in patients with chronic kidney disease. Am J Cardiol 119:1275-1280

126. Kim YS, Nam JS, Yeo DW, Kim KR, Suh SH, Ahn CW (2015) The effects of aerobic exercise training on serum osteocalcin, adipocytokines and insulin resistance on obese young males. Clin Endocrinol (Oxf) 82:686-694

127. Ahn N, Kim K (2016) Effects of 12-week exercise training on osteocalcin, high-sensitivity c-reactive protein concentrations, and insulin resistance in elderly females with osteoporosis. J Phys Ther Sci 28:2227-2231

128. Lin CF, Huang TH, Tu KC, Lin LL, Tu YH, Sen YR (2012) Acute effects of plyometric jumping and intermittent running on serum bone markers in young males. Eur J Appl Physiol 112:1475-1484

129. Chowdhury S, Schulz L, Palmisano B et al (2020) Musclederived interleukin 6 increases exercise capacity by signaling in osteoblasts. J Clin Invest 130:2888-2902

130. Cardoso DF, Marques EA, Leal DV, Ferreira A, Baker LA, Smith AC, Viana JL (2020) Impact of physical activity and exercise on bone health in patients with chronic kidney disease: a systematic review of observational and experimental studies. BMC Nephrol 21:1-11 
131. Gomes TS, Aoike DT, Baria F, Graciolli FG, Moyses RMA, Cuppari L (2017) Effect of aerobic exercise on markers of bone metabolism of overweight and obese patients with chronic kidney disease. J Ren Nutr 27:364-371

132. Liao MT, Liu WC, Lin FH, Huang CF, Chen SY, Liu CC, Lin $\mathrm{SH}, \mathrm{Lu} \mathrm{KC}, \mathrm{Wu} \mathrm{CC}$ (2016) Intradialytic aerobic cycling exercise alleviates inflammation and improves endothelial progenitor cell count and bone density in hemodialysis patients. Med (United States) 95:e4134

133. Marinho SM, Carraro Eduardo JC, Mafra D (2017) Effect of a resistance exercise training program on bone markers in hemodialysis patients. Sci Sports 32:99-105

134. Marinho SMS A, Mafra D, Pelletier S, Hage V, Teuma C, Laville M, Carraro Eduardo JC, Fouque D (2016) In hemodialysis patients, intradialytic resistance exercise improves osteoblast function: a pilot study. J Ren Nutr 26:341-345

135. Roghani T, Torkaman G, Movasseghe S, Hedayati M, Goosheh B, Bayat N (2013) Effects of short-term aerobic exercise with and without external loading on bone metabolism and balance in postmenopausal women with osteoporosis. Rheumatol Int 33:291-298

136. Tobeiha M, Moghadasian MH, Amin N, Jafarnejad S (2020) RANKL/RANK/OPG pathway: a mechanism involved in exercise-induced bone remodeling. Biomed Res Int. https://doi. org/10.1155/2020/6910312

137. Fiuza-Luces C, Garatachea N, Berger NA, Lucia A (2013) Exercise is the real polypill. Physiology 28:330-358

138. Scott JPR, Sale C, Greeves JP, Casey A, Dutton J, Fraser WD (2011) The role of exercise intensity in the bone metabolic response to an acute bout of weight-bearing exercise. J Appl Physiol 110:423-432

139. Bergström I, Parini P, Gustafsson SA, Andersson G, Brinck J (2012) Physical training increases osteoprotegerin in postmenopausal women. J Bone Miner Metab 30:202-207

140. Notomi T, Karasaki I, Okazaki Y, Okimoto N, Kato Y, Ohura K, Noda M, Nakamura T, Suzuki M (2014) Insulinogenic sucrose+amino acid mixture ingestion immediately after resistance exercise has an anabolic effect on bone compared with non-insulinogenic fructose + amino acid mixture in growing rats. Bone 65:42-48

141. Rubin J, Murphy T, Nanes MS, Fan X (2000) Mechanical strain inhibits expression of osteoclast differentiation factor by murine stromal cells. Am J Physiol - Cell Physiol 278:C1126-C1132

142. Mezil YA, Allison D, Kish K, Ditor D, Ward WE, Tsiani E, Klentrou P (2015) Response of bone turnover markers and cytokines to high-intensity low-impact exercise. Med Sci Sports Exerc 47:1495-1502

143. Marques EA, Wanderley F, Machado L, Sousa F, Viana JL, Moreira-Gonçalves D, Moreira P, Mota J, Carvalho J (2011) Effects of resistance and aerobic exercise on physical function, bone mineral density, OPG and RANKL in older women. Exp Gerontol 46:524-532

144. Johansen KL, Chertow GM, Ng AV, Mulligan K, Carey S, Schoenfeld PY, Kent-Braun JA (2000) Physical activity levels in patients on hemodialysis and healthy sedentary controls. Kidney Int 57:2564-2570

145. Segura-Ortí E, Gordon P, Doyle J, Johansen KL (2018) Correlates of physical functioning and performance across the spectrum of kidney function. Clin Nurs Res 27:579-596

146. Clark BC (2009) In vivo alterations in skeletal muscle form and function after disuse atrophy. Med Sci Sports Exerc 41:1869-1875

147. Park H, Park S, Shephard RJ, Aoyagi Y (2010) Yearlong physical activity and sarcopenia in older adults: the nakanojo study. Eur J Appl Physiol 109:953-961
148. Johansen KL, Chertow GM, Da Silva M, Carey S, Painter P (2001) Determinants of physical performance in ambulatory patients on hemodialysis. Kidney Int 60:1586-1591

149. John SG, Sigrist MK, Taal MW, McIntyre CW (2013) Natural history of skeletal muscle mass changes in chronic kidney disease stage 4 and 5 patients: an observational study. PLoS ONE 8:e65372

150. Nielsen AR, Mounier R, Plomgaard P, Mortensen OH, Penkowa M, Speerschneider T, Pilegaard H, Pedersen BK (2007) Expression of interleukin-15 in human skeletal muscle - effect of exercise and muscle fibre type composition. J Physiol 584:305-312

151. Pedersen BK, Febbraio MA (2012) Muscles, exercise and obesity: skeletal muscle as a secretory organ. Nat Rev Endocrinol $8: 457-465$

152. Huh JY (2018) The role of exercise-induced myokines in regulating metabolism. Arch Pharm Res 41:14-29

153. Pillon NJ, Bilan PJ, Fink LN, Klip A (2013) Cross-talk between skeletal muscle and immune cells: muscle-derived mediators and metabolic implications. Am J Physiol Metab 304:E453-465

154. Kopple JD, Wang H, Casaburi R, Fournier M, Lewis MI, Taylor W, Storer TW (2007) Exercise in maintenance hemodialysis patients induces transcriptional changes in genes favoring anabolic muscle. J Am Soc Nephrol 18:2975-2986

155. Moore DR, McKay BR, Tarnopolsky MA, Parise G (2018) Blunted satellite cell response is associated with dysregulated IGF-1 expression after exercise with age. Eur J Appl Physiol 118:2225-2231

156. Liu R, Schindeler A, Little DG (2010) The potential role of muscle in bone repair. J Musculoskelet Neuronal Interact 10:71-76

157. Macias BR, Swift JM, Nilsson MI, Hogan HA, Bouse SD, Bloomfield SA (2012) Simulated resistance training, but not alendronate, increases cortical bone formation and suppresses sclerostin during disuse. J Appl Physiol 112:918-925

158. Asamiya Y, Tsuchiya K, Nitta K (2016) Role of sclerostin in the pathogenesis of chronic kidney disease-mineral bone disorder. Ren Replace Ther 2:8

159. Hamrick MW, McNeil PL, Patterson SL (2010) Role of musclederived growth factors in bone formation. J Musculoskelet Neuronal Interact 10:64-70

160. Clarke MSF, Feerack DL (1996) Mechanical load induces sarcoplasmic wounding and FGF release in differentiated human skeletal muscle cultures. FASEB J 10:502-509

161. Viana JL, Kosmadakis GC, Watson EL, Bevington A, Feehally J, Bishop NC, Smith AC (2014) Evidence for anti-inflammatory effects of exercise in CKD. J Am Soc Nephrol 25:2121-2130

162. Shioi A, Katagi M, Okuno Y, Mori K, Jono S, Koyama H, Nishizawa Y (2002) Induction of bone-type alkaline phosphatase in human vascular smooth muscle cells: roles of tumor necrosis factor- $\alpha$ and oncostatin $M$ derived from macrophages. Circ Res 91:9-16

163. Watson EL, Viana JL, Wimbury D, Martin N, Greening NJ, Barratt J, Smith AC (2017) The effect of resistance exercise on inflammatory and myogenic markers in patients with chronic kidney disease. Front Physiol 8:541

164. Medina-Gomez C, Kemp JP, Dimou NL et al (2017) Bivariate genome-wide association meta-analysis of pediatric musculoskeletal traits reveals pleiotropic effects at the SREBF1/TOM1L2 locus. Nat Commun 8:1-10

165. Wang XH, Du J, Klein JD, Bailey JL, Mitch WE (2009) Exercise ameliorates chronic kidney disease-induced defects in muscle protein metabolism and progenitor cell function. Kidney Int 76:751-759

166. Louis E, Raue U, Yang Y, Jemiolo B, Trappe S (2007) Time course of proteolytic, cytokine, and myostatin gene expression after acute exercise in human skeletal muscle. J Appl Physiol 103:1744-1751 
167. Baxter-Jones ADG, Kontulainen SA, Faulkner RA, Bailey DA (2008) A longitudinal study of the relationship of physical activity to bone mineral accrual from adolescence to young adulthood. Bone 43:1101-1107

168. Boström P, Wu J, Jedrychowski MP et al (2012) A PGC1- $\alpha-$ dependent myokine that drives brown-fat-like development of white fat and thermogenesis. Nature 481:463-468

169. Colaianni G, Cuscito C, Mongelli T, Oranger A, Mori G, Brunetti G, Colucci S, Cinti S, Grano M (2014) Irisin enhances osteoblast differentiation in vitro. Int J Endocrinol. https://doi. org/10.1155/2014/902186

170. Moraes C, Leal VO, Marinho SM, Barroso SG, Rocha GS, Boaventura GT, Mafra D (2013) Resistance exercise training does not affect plasma irisin levels of hemodialysis patients. Horm Metab Res 45:900-904

171. Zhou Y, Hellberg M, Hellmark T, Höglund P, Clyne N (2019) Muscle mass and plasma myostatin after exercise training: a substudy of renal exercise (RENEXC) - a randomized controlled trial. Nephrol Dial Transplant. https://doi.org/10.1093/ndt/gfz210

172. Esposito P, La Porta E, Calatroni M et al (2017) Modulation of myostatin/hepatocyte growth factor balance by different hemodialysis modalities. Biomed Res Int 1:1-5

173. Wang H, Casaburi R, Taylor WE, Aboellail H, Storer TW, Kopple JD (2005) Skeletal muscle mRNA for IGF-IEa, IGF-II, and IGF-I receptor is decreased in sedentary chronic hemodialysis patients. Kidney Int 68:352-361
174. Han DS, Chen YM, Lin SY, Chang HH, Huang TM, Chi YC, Yang WS (2011) Serum myostatin levels and grip strength in normal subjects and patients on maintenance haemodialysis. Clin Endocrinol (Oxf) 75:857-863

175. Wang CJ, Johansen KL (2019) Are dialysis patients too frail to exercise? Semin Dial 32:291-296

176. Watson EL, Major RW, Wilkinson TJ, Greening NJ, Gould DW, Barratt J, Smith AC (2020) The association of muscle size, strength and exercise capacity with all-cause mortality in nondialysis-dependent CKD patients. Clin Physiol Funct Imaging 40(6):399-406

177. Lombardi G, Ziemann E, Banfi G (2019) Physical activity and bone health: what is the role of immune system? A narrative review of the third way. Front Endocrinol (Lausanne). https:// doi.org/10.3389/fendo.2019.00060

178. Viana JL, Martins P, Parker K et al (2019) Sustained exercise programs for hemodialysis patients: the characteristics of successful approaches in Portugal, Canada, Mexico, and Germany. Semin Dial 32:320-330

Publisher's Note Springer Nature remains neutral with regard to jurisdictional claims in published maps and institutional affiliations. 